\title{
Entrepreneurship
}

\section{Empowerment: construção, desenvolvimento e incremento do poder entre as pessoas}

O presente artigo tem como objetivo apresentar um modelo de gestão chamado empowerment, buscando compreender a sua importância no processo de tomada de decisões e a necessidade de sua aplicação dentro das organizações. Fundamentado em pesquisas bibliográficas, conceitos aqui expostos, referem-se ao tema empoderamento e ao modo como é disseminado em âmbito organizacional, evidenciando como esse pode otimizar as interações entre funcionários e produzir significativos resultados, configurando-se em avanços no desenvolvimento, crescimento profissionais e pessoais, bem como o organizacional. Infere-se que o tema pode ser amplo, quando analisado em diversos ângulos, assim será sempre discutido no cenário empresarial, pois praticar o empowerment, é levar inovação, criatividade, promover o desenvolvimento e o crescimento para equipes com alta performance organizacional.

Palavras-chave: Gestão de Recursos Humanos; Empowerment; Benefícios.

\section{Empowerment: construction, development and increase of power among people}

The present article aims to present a management model called empowerment, seeking to understand its importance in the decision making process and the need for its application within organizations. Based on bibliographical research, concepts discussed here refer to the theme of empowerment and how it is disseminated in an organizational context, showing how it can optimize interactions between employees and produce significant results, being configured in advances in development, professional growth and personal as well as organizational. It is inferred that the theme can be broad, when analyzed from several angles, so it will always be discussed in the business scenario, because to practice empowerment, is to lead innovation, creativity, promote development and growth for teams with high organizational performance.

Keywords: Human Resource Management; Empowerment; Benefits.

Topic: Liderança e Motivação

Reviewed anonymously in the process of blind peer.
Received: 10/01/2018

Approved: 21/04/2018

Uilton dos Santos Junior

Faculdade Maurício de Nassau, Brasil

http://lattes.cnpq.br/1578979704362758

uilton.junior@hotmail.com.br

Helena Maria Fagundes dos Santos Braz

Faculdade Maurício de Nassau, Brasil

http://lattes.cnpq.br/9373582225272500

helena-braz@bol.com.br

d.

DOI: 10.6008/CBPC2595-4318.2018.001.0002
Referencing this:

SANTOS JUNIOR, U.; BRAZ, H. M. F. S.. Empowerment: construção, desenvolvimento e incremento do poder entre as pessoas. Entrepreneurship, v.2, n.1, p.10-17, 2019. DOI: http://doi.org/10.6008/CBPC2595-4318.2018.001.0002 


\section{INTRODUÇÃO}

A administração ao longo dos anos vem sofrendo constantes evoluções e essas mudanças resultam da necessidade de atender as exigências que o mercado impõe diariamente, em qualquer época. Segundo Chiavenato (2010), o modelo organizacional tradicional do século XX, por exemplo, foi criado e adaptado para atender as necessidades da era industrial, onde as organizações eram criadas para durar sempre e vistas como perfeitas sem necessidade de qualquer melhoria ou ajustes, a forma de comando era totalmente centralizada e hierarquizada, cargos definitivos com tarefas simples, específicas, repetitivas e executadas pelos funcionários de forma submissa e sem direito a questionamentos ou opiniões. Ou seja, um modelo de administração arcaico e previsível sem perspectiva alguma de mudanças e inovações.

Atualmente, com o advento da Era da Informação e da Globalização, o universo organizacional tornou-se instável com as constantes mudanças que esse novo tempo impõe diariamente. Vivemos em um mundo imprevisível, extremamente competitivo, onde não existe mais espaço para o modelo rígido e definitivo de organização criado no século XX. Para Chiavenato (2010), a Era da Informação transformou o mundo dos negócios em um ambiente turbulento, abrindo espaço para organizações orgânicas e não mecânicas, tal como na Era Industrial.

Para Rodrigues et al. (2001), essas mudanças fizeram com que as organizações pensassem em um novo modelo de administração para continuar competindo neste novo mercado, um ambiente competitivo dinâmico e instável, que fez da inovação o principal elemento para o sucesso das empresas, tornando necessário um envolvimento maior das pessoas nos processos decisórios das organizações.

O Empowerment, de acordo com Moreto (2009, citado por SALES et al., 2014), tem o objetivo de capacitar pessoas no processo de tomada de decisões dentro das organizações, e resulta do processo de transformação das empresas para ambientes mais competitivos, instáveis e dinâmicos que, a Era da Informação e a Globalização, impõem às organizações.

Nesse contexto, o presente artigo tem como objetivo apresentar um modelo de gestão chamado empowerment, buscando compreender a sua importância no processo de tomada de decisões e a necessidade de sua aplicação dentro das organizações.

\section{METODOLOGIA}

Este artigo, fundamentado em pesquisas bibliográficas, traz conceitos que se referem ao tema empoderamento e ao modo como é disseminado em âmbito organizacional, evidenciando como esse pode otimizar as interações entre funcionários e produzir significativos resultados, configurando-se em avanços no desenvolvimento e crescimento profissionais e pessoais, bem como o organizacional.

\section{DISCUSSÃO TEÓRICA}

\section{Histórico do Empowerment}


O empowerment surgiu como uma forma de solucionar os problemas do sistema organizacional mecanicista criado no século XX, sistema esse em que a capacidade intelectual dos funcionários não era levada em consideração, a criatividade era sufocada, gerando insatisfação por parte dos trabalhadores, ou seja, as pessoas eram vistas com mero recurso de produção e não como parceiras da organização.

De acordo com Wilkinson (1997, citado por RODRIGUES et al., 2001), na década de 1920, Taylor, através de suas ideias, influenciou os administradores a pensarem nos melhores métodos de execução do trabalho, porém, havia diferença ente a decisão dos administradores e a execução dos trabalhadores. Chiavenato (2010) afirma que Taylor utilizava alguns princípios de racionalização do trabalho com o objetivo de definir métodos padronizados e treinar pessoas para obter a máxima eficiência possível. A adesão desses métodos por parte dos trabalhadores era dada através de incentivos salariais. Os cargos eram definidos através da divisão do trabalho e da fragmentação das tarefas, estabelecendo uma separação entre a gerência ('o pensar') e os trabalhadores (o executar). O gerente mandava e os funcionários obedeciam e executavam as tarefas simples e repetitivas.

Em 1930, surge a Escola das Relações Humanas, com o objetivo de trazer mudanças ao modelo mecanicista da administração tradicional, tentando substituir a chefia pela liderança, o comportamento social pelo comportamento em grupo a o incentivo salarial por recompensas sociais, entre outras mudanças. O modelo Humanístico surgiu como uma tentativa de submeter a administração autocrática e impositiva ao espírito democrático. A partir desse modelo, surgem os primeiros conceitos de liderança, motivação, comunicação e assuntos sobre as pessoas e sua supervisão (CHIAVENATO, 2010).

Apesar de o modelo Humanístico propor mudanças significativas, substituindo a ênfase nas tarefas e na estrutura organizacional pela ênfase nas pessoas e nos grupos sociais, a opinião do trabalhador não era considerada como um fator decisivo para a tomada de decisões.

O modelo humanista procura incrementar a interação das pessoas entre si e os superiores como meio de satisfazer as necessidades individuais e aumentar o moral do pessoal. Contudo, a consulta e a participação não afetam o cumprimento da tarefa nem o fluxo ou sequência do trabalho. Esses dois aspectos permanecem intocados no modelo humanista. (CHIAVENATO, 2010)

Segundo Oliveira et al. (2010), a partir da década de 1970, o modelo clássico de Administração passa por um momento de crise, e partir daí surge a necessidade e o interesse na participação dos trabalhadores nos processos de decisões dentro das organizações, um processo chamado democratização industrial. Em meados da década de 1980, surge o Empowerment, que até os dias atuais é utilizado como uma ferramenta de gestão, com a proposta de envolver os trabalhadores no círculo de qualidade das organizações promovendo mudança e um novo tempo para o universo organizacional.

Segundo Chiavenato (2010), o Empowerment é consequência da chegada de um tempo onde as inovações tecnológicas e desenvolvimento de novos produtos acontecem de forma rápida e intensa, os concorrentes fazem mudanças radicais e inesperadas em seus produtos e serviços, e as políticas governamentais mudam rapidamente. Com todas essas mudanças as organizações passaram a adotar um modelo de gestão mais orgânico e flexível adaptando-se ás novas características ambientais. 


\section{Conceito de Empowerment}

Chiavenato (2010) afirma que o Empowerment significa empoderar e consiste em atribuir poder ou, autoridade e responsabilidade às pessoas dentro de uma organização, com o objetivo de torná-las mais ativas e proativas, passando a ter mais autonomia e iniciativa em suas atividades organizacionais.

Segundo Sales et al. (2014), o Empowerment tem como objetivo a delegação do poder de decisão, a liberdade, a participação dos colaboradores no processo de administração e, busca ainda, um maior comprometimento por parte dos funcionários nas decisões organizacionais. Por assim, estabelece-se uma mudança de paradigma tradicional de gestão, para um paradigma focado na descentralização, desburocratização e flexibilização.

Para Tracy (1994 citado por SANTANA et al., 2010), o empowerment é uma mudança que leva o poder de decisão até o menor nível hierárquico dentro de uma organização, oferecendo a todos autonomia para executar suas tarefas, atribuindo-Ihes autoridade. A partir do momento em que a organização confere ao indivíduo autoridade para a tomada de decisões, ela está contribuindo para o desenvolvimento do colaborador, pois o processo de tomada de decisões exige discernimento, fazendo com que sua capacidade de avaliação seja ampliada.

Empowerment é um estilo de gestão participava, onde o gestor compartilha com os funcionários tanto as oportunidades quanto os impactos que o processo da tomada de decisões pode trazer para a organização. É um modelo de gerenciamento que visa a distribuição do poder e autoridade para todos os níveis organizacionais, de modo que as pessoas envolvidas se sintam responsáveis pela execução dos processos internos da empresa com qualidade (OLIVEIRA et al., 2010).

Horochovski et al. (2007) afirmam que o empowerment consiste em desenvolver o indivíduo aumentando sua capacidade de resolver conflitos pessoais ou organizacionais, abrangendo as dimensões políticas, culturais, econômicas e psicológicas de uma organização ou sociedade.

Em suma, o Empowerment trata-se de um novo modelo gestão baseado na coletividade, democracia e participação de todos os colaboradores de uma organização, visando a desburocratização e descentralização de seus processos internos, aumentando o nível de comprometimento dos seus colaboradores, objetivando a melhora do desempenho organizacional e o aumento da produtividade.

\section{Dimensões do Empowerment}

De acordo com Herrenkohl et al. (1999), a implementação do empowerment acontece em quatro dimensões, sendo a primeira conhecido como Visão Compartilhada, que é constituída por três elementos: 0 primeiro elemento é a clareza de metas, que é a expectativa sobre o desempenho do funcionário, os objetivos da empresa apresentado com clareza e a consciência do funcionário em relação ao objetivo que a empresa almeja alcançar; O segundo é a consecução de metas, que está ligado ao fato dos colaboradores se sentirem responsáveis pelo alcance das metas estabelecidas pela organização e o comprometimento com a 
empresa; e o terceiro e último elemento é a orientação ao consumidor compreende o conhecimento do que os clientes esperam e a responsabilidade que a empresa tem de entregar resultados aos seus consumidores.

A segunda dimensão é a Estrutura Organizacional e o Gerenciamento que Apoiam a Implementação do Empowerment, como elementos desta dimensão têm-se: o nível de responsabilidade, o trabalho em equipe, a tomada de ações de risco e a valorização dos funcionários pelos clientes.

Responsabilidade está relacionada ao nível da organização em que as decisões são tomadas, quem é responsável pelo bem estar da organização. Equipes estão relacionadas à eficácia do trabalho em equipe e se as equipes são responsáveis pelas decisões sobre suas próprias atividades de trabalho. A tomada de ação de risco trata do entusiasmo em assumir riscos para melhorar o desempenho e se a organização apoia ou pune a tomada de ação de risco. Clientes valorizam os funcionários que são orientados para clientes e que se sentem responsáveis por eles. (HERRENKOHL et al., 1999)

A terceira dimensão seria a Implementação do Empowerment, a qual é representada pelos seguintes elementos: a mudança em treinamento e desenvolvimento; a solução de problemas associada ao treinamento e desenvolvimento; e a confiança mútua dos funcionários no processo de resolver problemas.

A mudança em treinamento e desenvolvimento exige que a organização encoraje os empregados a procurar conhecimento que melhore desempenho e que forneça oportunidades para aprendizagem, assim como os funcionários buscarem mudanças que beneficiem os clientes. A solução de problemas está associada ao gosto por novos desafios, à aquisição de novas habilidades necessárias para executar seu trabalho. A confiança mútua implica que os funcionários sintam-se confortáveis ao discordarem dos outros, que sintam que se aprende com erros e que confiem que a falha não será indiscriminadamente punida. (HERRENKOHL et al., 1999)

Reconhecimento Institucional das realizações dos funcionários e a consequente demonstração de que eles são ouvidos, é a quarta dimensão, onde o conhecimento do sistema de recompensa relaciona-se à consciência dos funcionários do que a organização recompensa, aos fatos de que entregar valor ao consumidor é recompensado e de que todos na organização assumem responsabilidade por suas ações (HERRENKOHL et al., 1999).

\section{Modalidades de Empowerment}

Segundo Ford e Fottler (1996, citado por RODRIGUES et al., 2001), existem dois modelos que apresentam os diferentes tipos de empowerment: a autoridade para tomada de decisão sobre o contexto do trabalho e a autoridade para tomada de decisão sobre o conteúdo do trabalho, conforme a figura 01.

No ponto $A$, não existe nenhum poder de tomada de decisão relacionado ao trabalho nem em termos de conteúdo e contexto de trabalho. O ponto A representa um estágio onde o trabalho é altamente repetitivo, típico da linha de montagem tradicional (FORD et al., 1996, citado por RODRIGUES et al., 2001).

No ponto B, o trabalhador passa a receber poderes e responsabilidades nas decisões de conteúdo de trabalho, porém seu poder de decisão sobre o contexto do trabalho ainda é pouco. Esse ponto representa a estrutura do empowerment utilizado nos dias atuais (FORD et al., 1996, citado por RODRIGUES et al., 2001).

O empowerment participativo, representado pelo ponto $C$, corresponde a uma área mais específica de grupos de trabalhos autônomos, são os principais responsáveis pela identificação de problemas, busca de 
possibilidades e escolha e orientação da melhor possibilidade para o conteúdo de trabalho (FORD et al., 1996, citado por RODRIGUES et al., 2001).

O ponto $D$, definição da missão, retrata uma situação atípica e dificilmente abordada entre os autores na literatura de empowerment. Ford et al. (1996, citado por RODRIGUES et al., 2001) usam como exemplo uma equipe em uma operação de manutenção sindicalizada, que recebe a tarefa de decidir se uma determinada tarefa poderia ser melhor realizada por terceiros ou pelos próprios funcionários da empresa.

$\mathrm{O}$ ponto $\mathrm{E}$, autogerenciamento, é caracterizado pela total autoridade que os funcionários recebem para tomar decisões sobre o conteúdo do trabalho e contexto do trabalho.

Para fazer isto, há a necessidade de grande confiança na capacidade dos funcionários usarem o recém-conhecido empowerment no sentido de contribuir para a eficácia organizacional. Isto requer extensivo envolvimento dos empregados no desenvolvimento da missão e das metas da organização, e a confiança de que o funcionário está pronto, desejoso e capaz de tomar decisões em seu trabalho, que reflitam contribuições sábias, inteligentes e apropriadas aos objetivos da organização. (FORD et al., 1996, citado por RODRIGUES et al., 2001)

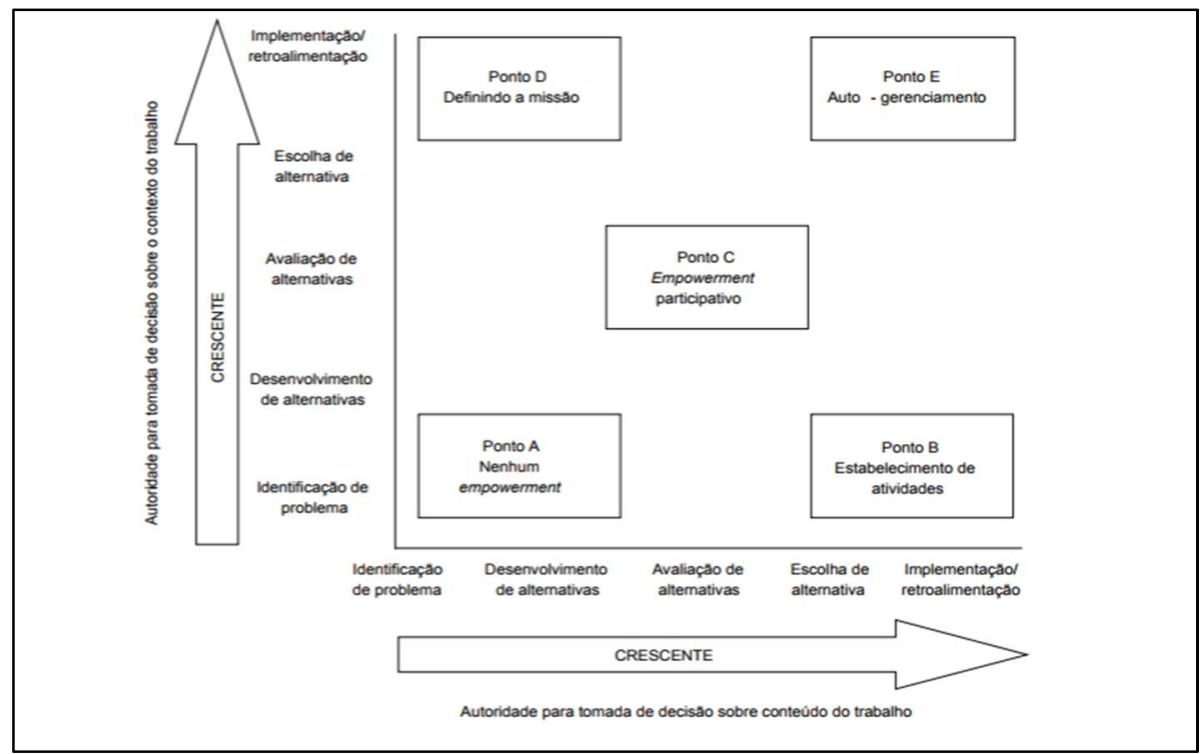

Figura 01: Tipos de empowerment do funcionário. Fonte: FORD et al., 1996, citado por RODRIGUES et al., 2001.

\section{O Empowerment e a Gestão de Recursos Humanos}

De acordo com Rodrigues et al. (2001), o empowerment se fortaleceu a partir da necessidade de romper as fronteiras funcionais dentro das organizações através de um processo de gestão horizontal que tem como objetivo a diminuição dos níveis hierárquicos e a participação dos funcionários no processo decisório da empresa.

O setor de recursos humanos possui ligação direta com o desenvolvimento do empowerment, dentro da empresa, pois são os principais responsáveis pela elaboração e organização de programas de redesenho de cargos, treinamento e desenvolvimento, remuneração e avaliação de desempenho (RODRIGUES et al., 2001).

A primeira principal mudança da gestão de recursos humanos ocorre no processo de estruturação da organização e de redesenho de cargos. A reestruturação organizacional e redesenho de cargos, que devem permitir a descentralização da responsabilidade, o 
aumento da capacidade decisória das pessoas e a horizontalização da organização e a incessante renovação das competências essenciais da empresa. (SANTOS, 1998)

O autor ainda afirma que o redesenho de cargos devem incorporar as seguintes competências: interacionais, de capacitação, de comunicação e técnicas. As competências interacionais estão relacionadas ao desenvolvimento da harmonia e coesão da equipe. O gestor deve promover a participação de todos além de saber o momento exato de intervir, se houver necessidade, além de ter a sensibilidade de identificar as forças e fraquezas de cada indivíduo ou grupo utilizando seus pontos positivos, melhorando os pontos negativos para maximizar o desempenho do grupo (COOPERS et al., 1997, citado por SANTOS, 1998).

Competências de capacitação mostra que os funcionários devem estar em um constante processo de capacitação para saber resolver incidentes inusitados, trabalhar sob pressão, lidar com os mais variados estilos de público e resolver conflitos (COOPERS et al., 1997, citado por SANTOS, 1998).

A competência de comunicação está relacionada à comunicação escrita e oral. O domínio e a segurança no processo de comunicação são fundamentais para a eficácia da gestão. As competências técnicas são as mais específicas, diferentes das competências gerenciais que possuem uma amplitude razoável a diversos tipos de organizações. As competências técnicas devem ser pensadas para cada tipo de empresa de forma individual e que se encaixe com a realidade do ambiente competitivo em que a empresa está inserida (COOPERS et al., 1997, citado por SANTOS, 1998).

O segundo programa de responsabilidade do setor de $\mathrm{RH}$ para o desenvolvimento do empowerment é o treinamento e desenvolvimento, esse processo é iniciado quando o gestor dá ênfase no processo de aprendizagem em oposição aos resultados.

[...] Um programa de carreira que possua a aprendizagem como foco central examina não somente o conteúdo assimilado pelas pessoas - capacidades, interesses, aspirações e necessidades, mas também ajuda-as a focar o conteúdo como resultado de um processo pelo qual se realizam escolhas dentre várias alternativas. Deste modo, o participante ajuda a aumentar a amplitude de escolhas, não somente em termos de resultados, mas também em termos dos processos através dos quais eles possa atingir esses resultados; [...]. (KOLB et al., 1977, citado por SANTOS, 1998)

Quinn et al. (1999, citado por SANTOS, 1998) afirmam que o desenvolvimento da capacidade de decisão dos funcionário, somente é possível a partir do momento em que os gestores compartilham informações a respeito da empresa, disponibilizam treinamentos inerentes às atividades desenvolvidas, estimulam a assunção de riscos por parte dos funcionários, recompensando-os, pois, faz parte do processo de aprendizagem. Essas são características clássicas do processo de empowerment dentro de uma empresa.

O sistema de remuneração é outra atividade de responsabilidade do setor de Recursos Humanos que potencializa o empowerment dentro das empresas. Santos (1998) afirma que existem dois sistemas de remuneração: o tradicional e a remuneração por habilidades. O processo de remuneração tradicional é totalmente conservador e contraditório a nova orientação estratégica das organizações, que estimula o trabalho em equipe e a inovação. $O$ sistema de remuneração por habilidades se encaixa perfeitamente ao novo paradigma das organizações, pois, é baseado nas pessoas, suas habilidades, capacidade de trabalhar em equipe, conhecimentos e competências. 
O processo da avaliação de desempenho também pode ser adaptado ao empowerment, para Randolph (1995 citado por RODRIGUES et al., 2001) essa adaptação é através da restruturação do programa de avaliação de desempenho, pois a estrutura de avaliação tradicional não prepara os colaboradores para o processo de tomada de decisões. Um plano de avaliação de desempenho reestruturado deve afastar a gerencia da avaliação do colaborador e visar a coparticipação e melhoria contínua.

\section{CONCLUSÕES}

O presente artigo objetivou apresentar um modelo de gestão chamado empowerment, buscando compreender a sua importância no processo de tomada de decisões e a necessidade de sua aplicação dentro das organizações. Diante das perspectivas apresentadas de renomados autores, infere-se que o tema poder é amplo, quando analisado em diversos ângulos e será sempre discutido no cenário empresarial, pois, praticar o empowerment, é levar inovação, criatividade, promover o desenvolvimento e o crescimento para equipes com alta performance organizacional.

Por fim, os benefícios oriundos da implantação do empowerment são muitos e abrangentes a toda uma organização, mas as consequências só surtirão efeito positivo se for levado a sério por todos que compõem a empresa, com apoio da alta direção, pois se incumbirá de preparar e incentivar as pessoas a adotarem a prática, objetivando o alcance de metas e de objetivos pré-definidos.

\section{REFERÊNCIAS}

CHIAVENATO, I.. Gestão de pessoas: o novo papel dos recursos humanos nas organizações. Rio de Janeiro: Elsevier, 2010.

HERRENKOHL, R. C.; JUDSON, G. T.; HEFFNER, J. A.. Defining and measuring employee empowerment. Journal of Applied Behavioral Science, v.35, n.3, p.373-389, 1999.

HOROCHOVSKI, R. R.; MEIRELLES, G.. Problematizando o Conceito de Empoderamento. In: SEMINÁRIO NACIONAL DE MOVIMENTOS SOCIAIS, PARTICIPAÇÃO E DEMOCRACIA, 2.

Anais. Florianópolis: Universidade Federal de Santa Catarina, 2007.

OLIVEIRA, C. P.; KROM. V.. O empowerment nas organizações. In: ENCONTRO LATINO AMERICANO DE INICIAÇÃO CIENTÍFICA, 14 e ENCONTRO LATINO AMERICANO DE PÓS-GRADUAÇÃO, 10. Anais. São José dos Campos: Universidade do Vale do Paraíba, 2010.
RODRIGUES, C. H. R.; SANTOS, F. C. A.. Empowerment: ciclo de implementação, dimensões e tipologia. Gest. Prod., São Carlos, 2001.

RODRIGUES, C. H. R.; SANTOS, F. C. A.. Empowerment: estudo de casos em empresas manufatureiras. Gest. Prod., São Carlos, 2004.

SANTANA, A. T.; SANTOS, V. A. C.. O emporwerment e a alta performance organizacional. Revista Administração e Ciências Contábeis, n.4, 2010.

SANTOS, F. C. A.. Dimensões competitivas e estratégia de recursos humanos: importância para a gestão de negócios em empresas manufatureiras. Tese (Doutorado) - Escola de Administração de Empresas de São Paulo, São Paulo, 1998.

SALES, V. M.; ALENCAR, L. C. Q.. Empowerment: O poder de decisão como ferramenta em uma organização. Monografia (Graduação) - Faculdade Cearense, 2014.

A CBPC - Companhia Brasileira de Produção Científica (CNPJ: 11.221.422/0001-03) detém os direitos materiais desta publicação. Os direitos referem-se à publicação do trabalho em qualquer parte do mundo, incluindo os direitos às renovações, expansões e disseminações da contribuição, bem como outros direitos subsidiários. Todos os trabalhos publicados eletronicamente poderão posteriormente ser publicados em coletâneas impressas sob coordenação da Sustenere Publishing, da Companhia Brasileira de Produção Científica e seus parceiros autorizados. Os (as) autores (as) preservam os direitos autorais, mas não têm permissão para a publicação da contribuição em outro meio, impresso ou digital, em português ou em tradução. 